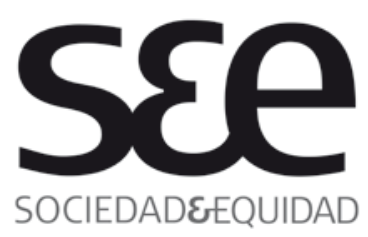

\title{
La generación de los hijos: identificaciones y participación de los descendientes de bolivianos y paraguayos en Buenos Aires (*)
}

The generation of the descendants: identifications and participation among sons and daughters of

Bolivians and Paraguayans in Buenos Aires

\section{Nombre:}

Filiación:

País:

Correo:

\author{
Natalia Gavazzo ${ }^{(*)}$ \\ Universidad Nacional de San Martin \\ Argentina \\ navegazzo@yahoo.com
}

\section{Resumen}

Teniendo en cuenta que son las dos comunidades de inmigrantes más numerosas y reconocidas de Buenos Aires, este artículo analiza algunas formas de identificación de los hijos de bolivianos y paraguayos. A fin de comprender el impacto que tiene la migración a largo plazo en las "nuevas" generaciones. Se basa en una tesis doctoral que examina la articulación de estas identificaciones con algunas formas de participación de los descendientes en organizaciones y proyectos colectivos de diversa índole. En este trabajo se retoman algunas características generales referidas a las identificaciones de los descendientes de bolivianos y paraguayos en la ciudad para comprender los modos en que el término "generación" define a estos descendientes como un grupo distinguible tanto dentro de la estructura familiar (es decir, como "hijos") como dentro de la estructura etaria (como "jóvenes"). Se propone estudiar las prácticas que se derivan de estas identificaciones y sus efectos en las relaciones sociales y en la

(*) Una versión anterior de este trabajo fue presentado en el $\mathrm{V}$ Congreso de la Asociación Latinoamericana de Población, Montevideo, Uruguay, del 23 al 26 de octubre de 2012.

(*) La autora es Doctora en Antropología (FFyL - UBA), Magíster en Estudios Latinoamericanos (University of London, Reino Unido) y Licenciada en Ciencias Antropológicas (FFyL - UBA). También es Profesora y Becaria Postdoctoral del CONICET en la Universidad Nacional de San Martin (IDAES-UNSAM). Sus líneas de investigación son: las migraciones desde países limítrofes hacia la Argentina, desde la práctica de danzas, el activismo y las relaciones comunitarias hasta el (trans)nacionalismo, el asociacionismo y las políticas públicas. 


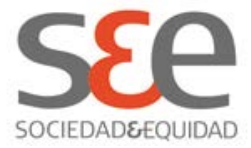

auto-presentación de los hijos en diversos ámbitos de actuación. Esto posibilitará analizar el lugar que ocupan las organizaciones de la sociedad civil en la lucha por los derechos de los migrantes (especialmente bolivianos y paraguayos) y sus familias (específicamente sus hijos), como al rol que ellos ocupan en la transformación de la sociedad porteña-argentina, considerando el contexto discriminatorio que ha definido a estos migrantes como no deseados.

\title{
Palabras Claves
}

Generación, Hijos de inmigrantes, Identificaciones, Participación.

\begin{abstract}
This article analyzes forms of identification among children of Bolivians and Paraguayans in Buenos Aires, two of the biggest immigrant communities in that city and in Argentina. It is based on a PhD thesis that aims to understand the impact of long-term migration by examining the articulation between those identifications and diverse forms of participation displayed by the descendants in organizations and collective projects created by their communities. In this article some of the general characteristics of Bolivian and Paraguay descendants' identifications in the city are revised, in order to comprehend how the notion of "generation" helps to define those descendants as a distinguishable group both within the family frame (as "sons" and "daughters") and within age structure (as "young"). The aim is to study some practices derived from those identifications and their effects on social relationships and self-definition of the descendants in different contexts. This will allow an analysis of the place that civil society organizations are playing in the struggle for migrants rights (specially Bolivians and Paraguayans) and their families (specially their children) and, at the same time, the role that the descendants are playing in the transformations of local society, considering the discriminatory context within which these migrants were -and still are- defined as "unwanted"
\end{abstract}

\section{Keywords}

Generation, Descendants of immigrants, Identifications, Participation 


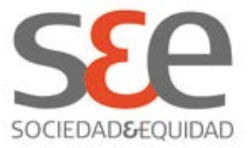

\section{Introducción: diferencia cultural y migración a través de las generaciones}

Debido a la importancia que se observa no sólo en el volumen del flujo inmigratorio en Argentina sino además en el impacto que tiene ese flujo en la sociedad "de destino", existe un vasto campo de estudios migratorios a los que este trabajo refiere en mayor o menor medida. Los primeros avances se dieron en el campo de la historia (Devoto, 2003) y la sociología (Germani, 1987[1955]), y aunque inicialmente se enfocaron en las migraciones del siglo XIX y primer mitad del $X X$, en los últimos diez o quince años las migraciones intra-regionales han sido crecientemente analizadas. Entre los enfoques que proliferaron se debe mencionar el de los demógrafos, geógrafos, politólogos, comunicólogos, especialistas del derecho y economistas. Los antropólogos se han incorporado bastante después a este campo de estudios (Bargman, y otros 1992), sobre todo en cuanto a la compresión de la dimensión cultural de las migraciones.

A ese respecto, partimos de que la inmigración es "constitutiva de nuestra sociedad actual, parte integral del proyecto nacional decimonónico que, a medida que el tiempo ha pasado, ha contribuido a construir cierta identidad" (Oteiza, Novick y Aruj, 1997:7). Inmigrantes de todo el mundo han participado del desarrollo y crecimiento de la nación argentina desde su nacimiento, tanto como mano de obra para el sector agrícola como también -al menos para las elites liberales- como una fuerza para "civilizar" a la población nativa. Funcionarios e intelectuales que promovieron la inmigración transoceánica a fines del siglo XIX y principios del XX pensaron que los inmigrantes europeos iban a "blanquear" a la población local. El discurso de apertura se correspondió entonces con una normativa de recepción de los inmigrantes y de garantía de sus derechos básicos (Segato, 2002; Courtis y Pacecca, 2007; Domenech, 2008; Gavazzo, 2009).

En este sentido, los estudios sobre la inmigración en Argentina se han realizado durante muchas décadas a partir de un "paradigma asimilacionista", que sostenía que la fusión de los inmigrantes (en ese momento, europeos) se debía en gran medida a su peso demográfico, a su inserción en un único sistema de estratificación social, a su débil identificación con sus naciones de origen, a la cultura abierta de la sociedad argentina y a la infrecuente evaluación de la misma como "cultura a imitar" (Canelo, 2011). Pero a partir de la década de 1980 los estudios migratorios en Argentina comenzaron a cuestionar la idea del "crisol", tomando por foco a grupos étnicos particulares e incorporando como cuestión a la diferencia cultural. Desde entonces la historia económica perdió centralidad a favor de una nueva historia social y de una emergente antropología histórica, más cercanas al modelo del "pluralismo cultural" que al del "crisol" (Caggiano, 2005). Simultáneamente se pasó de un paradigma fundamentalmente cuantitativo a uno más cualitativo, que además involucra 


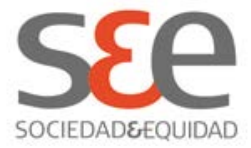

una gran variedad de abordajes, todo lo que resulta en la proliferación de nuevos estudios de caso.

Recuperando estos recorridos, en este artículo se expone parte de una tesis doctoral (Gavazzo, 2012) que se encuadró dentro de lo que podría denominarse como una mirada antropológica de las migraciones a través de las generaciones $^{2}$. En la misma se analizaron algunas identificaciones que se construyen entre jóvenes argentinos hijos de inmigrantes bolivianos y paraguayos en el Área Metropolitana de Buenos Aires (AMBA) ${ }^{3}$ en relación al origen de sus padres. Considerando varios ejes como el nacional, de clase, étnico, de género, etario, entre otros, se propuso además comprender los efectos particulares de esas identificaciones en aquellos descendientes que participan en organizaciones vinculadas a las comunidades de origen de sus padres, puesto que las mismas pueden ser usadas como herramientas modelando formas de participar social y políticamente válidas y vigentes. ¿Cómo impactan entonces esas identificaciones con el origen migratorio de los padres en las maneras de participar que tienen los jóvenes hijos de migrantes bolivianos y paraguayos en el AMBA? A partir de este análisis, en este artículo se propone conocer algunas posibilidades de agencia de estos "hijos" de inmigrantes, y de su ingreso como sujetos políticos en la arena pública, específicamente en la lucha contra la discriminación y por el reconocimiento de los derechos de "sus" comunidades. ¿Cómo se articulan esas identificaciones con sus acciones colectivas?

Para responder, deberemos considerar además cuándo y cómo el Estado argentino, a través de sus políticas y sus instituciones, interpela y convoca a la participación a la así llamada "segunda generación de inmigrantes". Puesto que el "crisol de razas" se encuentra en constante reactualización, resulta central el hecho de que en su devenir histórico la construcción de la identidad nacional argentina ha renegado frecuentemente de la presencia de las poblaciones de

\footnotetext{
${ }^{2}$ Por razones de limitación de espacio, en este artículo no podré detallar la totalidad de la bibliografía específica recopilada en la tesis y que funciona como base de la investigación que sustenta algunas de las afirmaciones del mismo. En todo caso, para conocer las referencias bibliográficas de los temas referidos en él -como la antropología de las migraciones en el país, y/o la inmigración boliviana y paraguaya en Argentina, y/ o las prácticas artísticas y culturales de los migrantes, y/ o su inserción laboral, y/ o la experiencia de los niños migrantes en las escuelas y/o de las mujeres migrantes- ver Gavazzo, 2012.

${ }^{3}$ Esta área comprende a la Ciudad Autónoma de Buenos Aires (CABA) y a veinticuatro municipios lindantes de la Provincia de Buenos Aires (también conocido como Gran Buenos Aires - GBA). En esta área se concentran más del 75\% de los paraguayos y más del $55 \%$ de los bolivianos que residen en todo el territorio nacional.
} 


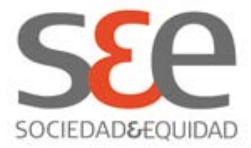

origen boliviano y paraguayo. 0 bien, si la ha visibilizado en ocasiones lo ha hecho de maneras estigmatizantes que -como será remarcado en este artículotienen un impacto específico en sus descendientes, que -a pesar de ser nativos argentinos- se ven atravesados en sus identificaciones y sus formas específicas de participación.

J ustamente a lo largo de la historia argentina ha existido un importante sistema migratorio en el Cono Sur gracias al cual Argentina podría ser definida como un país "receptor" también en relación a las naciones vecinas (Balán, 1982). Argentina se ha constituido como destino de distintas corrientes migratorias, principalmente de las provenientes de países limítrofes y del Perú. El direccionamiento de flujos migratorios de carácter limítrofe hacia las grandes áreas urbanas de la Argentina, especialmente el AMBA a partir de la década de 1940 y 1950, hacen de las mismas importante ejes de recepción de inmigrantes (Bruno, 2008). La inmigración de personas provenientes de estos dos países en la ciudad capital argentina se vincula con cambios en los modelos económicos y políticos de las naciones en cuestión (Martinez Pizarro y Villa, 2001; Benencia, 2003; Halpern, 2005). Y dentro de la población nacida en el extranjero, actualmente las dos poblaciones mayoritarias, tanto a nivel nacional como de Buenos Aires, son la boliviana y la paraguaya (Gavazzo, $2012)^{4}$. Por ello un estudio comparativo entre ambas comunidades resulta de vital importancia, más aún cuando en el campo de estudios local existen pocos trabajos que distingan ambas comunidades dentro del conjunto denominado "migrantes limítrofes" o bien que se dediquen a tomar a más de una como referencia.

Otro hecho que resulta significativo es que -a pesar de la importancia de este vasto campo de estudios migratorios y de que la migración boliviana y paraguaya a la Argentina cuenta con una historia que abarca varias décadas y generaciones- el tema de las "segundas generaciones" aún no ha sido explorado del mismo modo que lo fue para otros flujos de inmigración, como el de los descendientes de inmigrantes provenientes de Asia (Lamounier, 2002; Onaha, 2000; Gómez, 2008) y Europa (Devoto, 2003; Maluendres, 1994). Es central entonces sistematizar la información disponible y la discusión que se está manteniendo tanto a nivel local como global, puesto que la cuestión de los descendientes de inmigrantes viene siendo estudiada con gran interés en otras

${ }^{4}$ Según el Censo 2010, 1.805.957 extranjeros residen actualmente en el país, a diferencia de épocas pasadas en que la mayoría eran de origen europeo, 1.245.054 (o sea casi un $69 \%$ de los actuales migrantes provienen de países limítrofes. Entre ellos se destacan los paraguayos con más de 550.000 residentes y los bolivianos con más de 360.000 , constituyendo juntos casi el 50\% de la población extranjera en el país. 


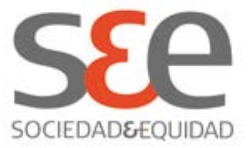

regiones del mundo ${ }^{5}$. En Estados Unidos y Europa, por ejemplo, la temática está siendo debatida intensamente impulsada por la "urgencia" percibida desde la política pública para estructurar un "buen gobierno" en relación a la creciente inmigración ${ }^{6}$.

Si tomamos el caso de Estados Unidos, podemos seguir a Portes (1997) que advierte sobre las dificultades para los hijos de crecer en una familia de inmigrantes puesto que buscan equilibrar la orientación de los padres extranjeros con las demandas de "asimilación" de la sociedad receptora. Así, la "segunda generación" vive una tensión entre ambas expectativas, lo que puede culminar 0 bien en el rechazo de la cultura parental o bien en un repliegue hacia adentro de la comunidad migratoria para no confrontar con la sociedad exterior (Portes, 1997:248). Aunque algunos estudios asumen que la "asimilación" Ileva progresivamente a la "aculturación", lo que a su vez Ilevaría hacia la movilidad socioeconómica de los hijos, Portes afirma que en las circunstancias presentes los resultados son opuestos pues frecuentemente se impide su inserción en la sociedad, no únicamente al mercado laboral sino también mediante la (des)valoración de su identidad cultural. Pero, ¿sucede lo mismo en a los casos de estudio? ¿Cuál es la identidad cultural de los hijos de inmigrantes bolivianos y paraguayos del AMBA y cómo afecta esa identidad a su "asimilación"? ¿Qué comparten padres e hijos que los podría hacer "no encajar"?.

Si analizamos la historia argentina y el lugar del AMBA en la atracción de inmigración de países de la región, especialmente Bolivia y Paraguay, comprendemos que ante todo ambos colectivos de inmigrantes comparten una cierta "imagen pública" -entendida como un conjunto de representaciones

5 Se deben usar entonces tanto los estudios realizados para otras comunidades en Argentina (como los referidos más arriba) como para otros migrantes en el mundo (Portes, 1997; Levitt y Waters, 2002; García Borrego, 2003; Lewis, 2007; Foner, 2009; Pedone, 2010a y b; Pedreño Canovas, 2010; Castellanos Ortega, 2010; Torres Perez, 2010; Castellanos Ortega, 2010; García Borrego, 2010; Sayad, 2011; entre otros). Para más detalles sobre esta bibliografía, ver Gavazzo, 2012.

${ }^{6}$ Algunos hechos recientes dan cuenta de esta urgencia para los gobiernos. En Europa, podemos resaltar distintos hechos de violencia en las calles y en las escuelas contra inmigrantes (principalmente africanos y sudamericanos) en España, y también en los suburbios de grandes ciudades de Francia, especialmente París. Tanto allí como en Estados Unidos aparece una preocupación respecto de su presencia en el espacio público, lo que podría derivar en una competencia por recursos, incluso en términos políticos. Tal es el caso de la participación de los jóvenes hijos de mexicanos en las distintas movilizaciones de reclamo por los derechos de los inmigrantes de ese origen en los Estados Unidos. 


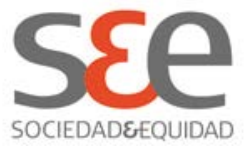

sociales que son formas de percibir, conceptualizar y significar los procesos sociales desde modelos ideológicos construidos históricamente- (Sinisi 1999). Asimismo, debido a que no existe representación sin práctica social, esos modelos e imágenes generan simultáneamente prácticas concretas (1999:45). Así, cuando las representaciones de propio grupo son valorizadas socialmente como positivas, se espera entonces que los sujetos de referencia sean "reconocidos" y "legítimos". En contraste cuando son imaginados mediante estereotipos negativos el efecto que provocan es la estigmatización.

A este respecto, ha sido suficientemente documentado que tanto bolivianos y paraguayos como otros inmigrantes de la región comparten el estigma de "ser inmigrante no deseados" y, en oposición a los europeos, son concebidos en ocasiones como un todo, como un grupo único (Caggiano, 2005). Por medio de esta operación de unificación y homogeneización, los inmigrantes latinoamericanos fueron definidos como un símbolo del "atraso", "primitivismo" y "subdesarrollo" del que este país supuestamente emergió en parte gracias a los inmigrantes transatlánticos que aportaron la cuota de "civilización", "modernización" y "progreso" a la nación argentina desde fines de siglo XIX7. En este punto, es posible afirmar que lo que comparten los inmigrantes y sus hijos en los casos seleccionados -tal como se busca mostrares un determinado estigma, es el ser concebidos como "otros", aunque -como veremos- la influencia de este estigma varía de acuerdo a los diferentes estereotipos culturales (algunos asociados a la nacionalidad y otros a la clase social, la edad o la etnicidad y la raza, entre otros).

Por esta razón, para analizar el modo en que se define socialmente a esta "segunda generación" de inmigrantes y lo que puede haber de estigmatizante en esa denominación (García Borrego, 2003), se precisa entonces comprender lo que ese término representa y cómo se transmite y reproduce. Esto puede ayudarnos a entender las implicancias de la denominación "inmigrantes de segunda generación" aplicada a los hijos que nunca inmigraron y que, por esta operación, quedarían unificados con sus padres bajo la categoría común de "inmigrantes". Sobre esta clasificación que equipara a los hijos de inmigrantes con sus padres, y los opone a los "autóctonos", tal como mostraremos, se sustenta frecuentemente su

\footnotetext{
${ }^{7}$ En este punto es importante relacionar el concepto de discriminación con el de racismo. Mientras que de este último existe una amplia gama de literatura, sobre el primero no la hay tanta (Margulis y Urresti, 1999). Por este motivo, y porque en ocasiones se complementan, es importante considerar similitudes, diferencias y cruces entre ambas nociones.
} 


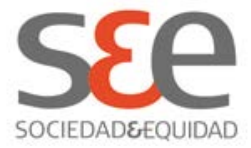

estigmatización ${ }^{8}$. Pues al tratar como inmigrantes a esos descendientes el estigma se transmite "de generación en generación", y es por eso que resulta imprescindible atender a las categorías que se utilizan para nombrar a los grupos sociales con que trabajamos. Como continuación de la tesis mencionada (Gavazzo, 2012), en este artículo utilizaremos la categoría "hijo" por considerarla más pertinente, no sólo por ser la de uso "nativo" sino también para superar este sesgo discriminatorio que la noción de "segunda generación" parece esconder.

Incluso, los ideales promovidos por la denominada "primera generación" podrían entrar en contradicción con la experiencia cotidiana de los niños, por ejemplo, en las escuelas ${ }^{9}$. Justamente en relación a las imágenes que supuestamente "comparten" con sus padres, se debe estudiar la forma en que los hijos de inmigrantes son percibidos y "regulados" por ciertas normas sociales para ver no sólo las dificultades que enfrentan sino el tratamiento que se hace de ellas (García Borrego, 2003). Porque pueden ser vistos como un "elemento distorsionador de la vida social del país" que no termina de encajar en el modo en que la sociedad se imagina (o representa) a sí misma. Frecuentemente la presencia de poblaciones surgidas de la inmigración plantea problemas a los nacionalismos en la medida en que -como afirma García Borrego siguiendo a Sayad- se les atribuyan "raíces culturales" de las que se piensa que tienen difícil encaje en la sociedad, como es el caso de paraguayos y bolivianos en el AMBA. La alteridad étnica que se percibe como el objeto del poder político se proyecta sobre los hijos incluso a veces de un modo mayor que hacia sus padres debido a su "condición fronteriza": una situación a mitad de camino entre inmigrantes y nativos (García Borrego, 2003). Es así que, aunque "no son inmigrantes venidos de fuera", la biologización de la relación padre-hijo (que naturaliza la herencia cultural de una generación a otra) hace que tampoco se pueda considerar a estos hijos como "puramente autóctonos", es decir como "culturalmente nativos", por mucho que legalmente puedan

\footnotetext{
${ }^{8}$ Entendida como la atribución a "otros" de una identidad negativamente cargada que, superponiéndose a cualquier otro rasgo suyo, se convierte en su atributo principal y definitorio (Goffman, 1980, citado en García Borrego 2003:30).

${ }^{9} \mathrm{Al}$ respecto de los niños migrantes y/ o sus hijos que residen en áreas suburbanas 0 segregadas de la ciudad -como es el caso de los hijos de bolivianos y paraguayos- debe decirse que aunque compartan el espacio escolar y barrial con otros niños de recursos escasos (es decir del mismo estrato socio-económico) son objeto de una "marcación étnica". Los niños "nativos" o "autóctonos" de otros orígenes (y a veces los propios docentes) además de burlarse de su acento, les adjudican un estereotipo negativo (por ejemplo, el de ser demasiado "dóciles" o "pasivos") que hace que los ejes nacionales o étnicos se entrecrucen con las marcas de clase en las identificaciones de los hijos.
} 


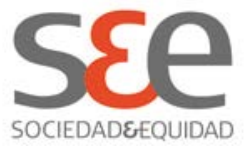

serlo ${ }^{10}$. Esta supuesta "condición fronteriza" sería lo que entonces los convierte en "problemáticos" y como consecuencia un objeto preferente de una política de "normalización" ${ }^{11}$. ¿Qué son y qué deberían ser estos jóvenes? ¿Argentinos, bolivianos, paraguayos, ninguna de las tres, todas a la vez, otra? En todo caso, frente a la transmisión inter-generacional del estigma, los hijos enfrentan un dilema: si se mantienen "bolivianos" o "paraguayos" se enfrentarán al "ostracismo social" y continuarán "los ataques en la escuela" (Portes, 1997). Pero si se convierten en "argentinos" deberán alejarse de los sueños de sus padres de progresar sin perder la solidaridad étnica y la preservación de valores tradicionales

Sea como fuere, y con bastante claridad, esta situación representa un desafío considerable no sólo para los hijos sino también para quienes emprendan un análisis de sus diversas estrategias de "asimilación" 0 "integración", ya que postula como central el plano cultural para comprender la "absorción" de los grupos de inmigrantes en la sociedad receptora y en eso la antropología, como decíamos, realiza su aporte. Es que además los procesos de "marcación étnica" o de "alterizacion" pueden verse afectados cuando -tal como veremos en los casos de estudio- la comunidad en la que nacen estos hijos se caracteriza por la solidaridad comunitaria y por redes sociales que fomentan la preservación de la identidad nacional para el éxito individual (Portes, 1997). ¿Hasta qué puntos las organizaciones contribuyen a una salida exitosa de la estigmatización para los hijos?

Para analizar el modo en que las diversas identificaciones de los hijos de bolivianos y paraguayos en el AMBA se relacionan con sus formas de participar de organizaciones y proyectos colectivos, comenzaremos por estudiar el entramado de instituciones que emergieron históricamente de ambas migraciones. Mostraremos la proliferación de redes sociales establecidas en barrios de la ciudad que permiten la creación de asociaciones que vinculan a los migrantes de origen boliviano y/ o paraguayo, y que constituyen marco en el cual se insertan los hijos como miembros activos ${ }^{12}$. La intención es construir

\footnotetext{
${ }^{10}$ Siguiendo a Sayad, García Borrego afirma que los hijos pueden ser incluso percibidos como un "subproducto endógeno" de la inmigración, una anomalía difícil de encajar en los parámetros del "etnicismo político" que supone la homogeneidad cultural de la nación (2003).

${ }^{11}$ En ese sentido, es útil considerar el concepto de biopolitica, entendida como la forma de poder político propia de la modernidad que opera fundamentalmente mediante "intervenciones normalizadoras" sobre las poblaciones (Foucault, 1991 [1978]).

${ }^{12} \mathrm{Al}$ respecto, debe decirse que ha habido interesantes trabajos en los que se analiza la inserción escolar de los niños migrantes e hijos de migrantes en la ciudad de Buenos
} 


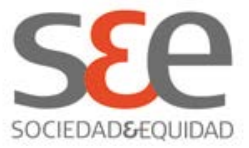

una visión comparativa que resalte la gran heterogeneidad de organizaciones y de tipos de liderazgo que se presentan en ambas comunidades en estudio, y sus implicancias para la participación de la generación de sus "hijos". Se examinarán finalmente testimonios de algunos descendientes que han participado de estas organizaciones al respecto de las actividades que realizan, los objetivos que tienen, de sus vínculos con el país de origen de sus padres, con sus comunidades en el lugar de residencia y de sus relaciones con las otras generaciones de dirigentes (sus padres y abuelos).

\section{Asociacionismo en las comunidades boliviana y paraguaya en el AMBA}

En cuanto a las organizaciones de las colectividades en estudio, se debe decir que existe un indefinido pero importante universo de instituciones y asociaciones $^{13}$. Es que "para dar continuidad a la identidad y hacer posible la migración secuencial, una comunidad de migrantes necesita conservar intactas sus relaciones con la comunidad de origen, para lo cual es necesaria la creación de instituciones informales, que en la primera etapa faciliten este pasaje y eviten la ruptura" (OIM-CEMLA, 2004:12). A medida que la permanencia en el nuevo territorio se prolonga, se vuelve necesario que las colectividades superen el nivel informal de sus instituciones, para vincularse tanto con las instituciones formales como con las comunidades locales. Este es el caso de los bolivianos y paraguayos del AMBA. Al respecto, a pesar de la abundancia de asociaciones en ambas colectividades, y aunque han habido investigaciones y análisis de algunas de sus organizaciones sociales, la participación social de los inmigrantes limítrofes ha despertado poca atención en el vasto campo de los estudios sobre migraciones internacionales a la Argentina que se ha ocupado mayormente de temas como la inserción laboral y la distribución espacial, por mencionar solo dos. Entre las excepciones se encuentran Halpern (1999), Pereyra (2001), Recalde (2002), Caggiano (2004), OIM-CEMLA (2004), Gavazzo (2006) y Pizarro (2007) quienes advierten la necesidad de establecer vínculos entre la emergencia de las organizaciones comunitarias y la historia de cada uno de los dos flujos de migración en estudio. Justamente en algunos de estos estudios se

\footnotetext{
Aires, especialmente de bolivianos (Novaro y otros, 2008; Beherán, 2007; Sinisi, 1999) que resultan realmente útiles para pensar en los estereotipos que entran en juego en las identificaciones y participación de los hijos. Por bibliografía sobre fiestas, danzas, bailes y vida comunitaria ver: Lamounier, 2002; Grimson, 1999; Gavazzo, 2002.

${ }^{13}$ Es muy difícil determinar un numero cierto de organizaciones, debido en primer lugar a lo efímeras que son algunas y a la informalidad de su funcionamiento, pero además porque no ha habido demasiado interés en investigar la cuestión. Una excepción la constituye el Censo realizado por OIM-CEMLA (2004) que muestra parte de la riqueza de este campo aun inexplorado.
} 


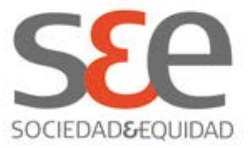

resaltan diferencias en el tipo de organizaciones entre bolivianos y paraguayos debido a las características e historia de ambos países y de ambas migraciones.

En cuanto a los paraguayos, puede decirse que sus organizaciones parecen estar moldeadas por el hecho de que muchos de sus líderes son exiliados políticos lo cual les da un perfil particular (Pereyra, 2001). Las primeras organizaciones en Argentina -como el Centro Paraguayo en 1887- por ejemplo, fueron creadas después de la Guerra de la Triple Alianza, cuando facciones de partidos políticos que habían sido proscriptos emergieron en el exilio. Durante la dictadura de Stroessner, las facciones políticas fueron un lugar importante para la resistencia y la lucha por el retorno a la democracia. En este sentido, tal como los anarquistas y comunistas europeos, estos líderes tenían bases de formación política sobre las cuales construir una estrategia de acción en el contexto migratorio. Por otro lado, en la década de 1950, dos nuevas organizaciones fueron creadas: el Hogar Paraguayo Eusebio Ayala en 1953 y la Casa Paraguaya en 1954, dedicadas sobre todo a la asistencia a los recién llegados y por ende al fortalecimiento de las redes comunitarias. En 1961 nació otra institución importante: el Club Atlético Deportivo Paraguayo cuyas actividades van más allá de los deportes y también incluyen metas sociales políticas y culturales (Halpern, 1999). Estas tres instituciones continúan funcionando aún hoy y tienen una influencia importante en la vida social y cultural de la comunidad.

Simultáneamente en la década del 60 , se crearon otros "centros" vinculados a regiones y pueblos de Paraguay razón por la cual mantienen un lazo más fuerte con los lugares del origen de los emigrados, fortaleciendo así la tendencia a migrar hacia el mismo destino que sus parientes o coterráneos ${ }^{14}$. Por otra parte, en 1997 nace la Federación de Entidades Paraguayas en la República Argentina (FEPARA), una organización que pretende vincular instituciones tanto de Buenos Aires como del interior del país ${ }^{15}$. Aquellas que se registran en dicha Federación son generalmente las que tienen personería

\footnotetext{
${ }^{14}$ Uno del muy pertinente es el Centro Santarroseño que fue creado en 1966 y eso fue uno del primer "centros" que poseyó realmente que un lugar para encontrar. En el caso boliviano también tenemos este tipo de instituciones como el Centro de Estudio Cruceños.

15 Según la autora, existen 113 organizaciones paraguayas entre las cuales 80 están federadas, pero de acuerdo a otras fuentes (como algunos medios de la comunidad) existen casi 500 en todo el país. La colectividad paraguaya no cuenta con un Censo como el mencionado para el caso boliviano.
} 


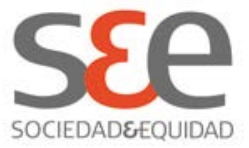

jurídica con un lugar físico ("sede" o "local") para poder reunirse ${ }^{16}$, y muchas de ellas están identificadas con los "barrios" en los que encuentran su lugar en Argentina y que en ocasiones están incluidos en su nombre ${ }^{17}$. Como analizamos en la mencionada tesis (Gavazzo, 2012), y del mismo modo que en la comunidad boliviana, esos "barrios" terminan siendo conocidos -en cierto sentido- como "barrios paraguayos" en el imaginario urbano de la ciudad de Buenos Aires. ${ }^{18}$ Finalmente, como señala Pereyra, la política juega un papel importante en el funcionamiento de las organizaciones paraguayas en tanto que la afiliación a partidos políticos -y a sus desprendimientos en Argentina- define diferentes perfiles e identidades entre ellas.

Con respecto a las organizaciones bolivianas, puede decirse que el "background político" de sus líderes y fundadores es también un factor importante. La primera que se registra -la Asociación Boliviana de Buenos Aires- data de 1933 y fue creada por ex oficiales militares de la Guerra del Chaco. Durante las décadas de 1960 y 1970, las organizaciones bolivianas podían ser agrupadas en dos tipos: por un lado, las relacionadas con movimientos "villeros" $y$, por otro, las que se auto-reconocen como organizaciones culturales. Las últimas estaban vinculadas a organizaciones previas y, según Pereyra, la mayoría ganó prestigio después de que aquellas primeras organizaciones se debilitaron. Entre estas, se destaca la Colectividad Boliviana de Morón y la Asociación de Reivindicación Marítima las que aún hoy continúan trabajando a la cabeza de las demás organizaciones de la comunidad boliviana en Buenos Aires. En 1978 se crea también LIDERBOL, la primera liga de futbol de la comunidad. En cuanto a las organizaciones barriales, puede decirse que adquirieron visibilidad en el contexto de un creciente movimiento en las villas, dentro del cual, muchos líderes bolivianas aún hoy son reconocidos (Vargas, 2006). Durante el proceso de erradicación de estos barrios populares, el movimiento se fortaleció y debilitó al mismo tiempo debido a que, por un lado, muchas de estas villas fueron destruidas pero, por el otro, diversos asentamientos fueron defendidos con éxito y se convirtieron en modelos para la acción de otros.

${ }^{16}$ La lucha para conseguir una sede es una constante en casi todas las entrevistas realizadas para este estudio, incluso en la memoria de aquellas instituciones que ya cuentan con un espacio físico.

${ }^{17}$ Tal es el caso del Centro Cultural Paraguayo de Morón y el Centro Unidad Paraguaya Social y Cultural de Quilmes.

${ }^{18}$ Aunque emigrantes de otros orígenes, aún internos, tengan su propio peso en el proceso de imaginar algunos barrios, las organizaciones paraguayas proyectan una imagen de la comunidad que permite hablar acerca de estas cartografías de la ciudad. Y lo mismo sucede con los bolivianos. 


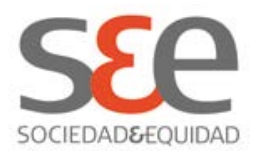

En tiempos democráticos, las organizaciones y los medios de comunicación bolivianos se fortalecieron y al mismo tiempo algunas ferias comerciales y torneos de fútbol comenzaron a formalizarse. En 1995 se crea la Federación de Entidades Bolivianas (FACBOL), a pesar de que tempranamente en 1997 se divide, dando origen a FIDEBOL (Federación Integrada de Entidades Bolivianas). A pesar de las divisiones internas entre las federaciones, existen diversos intentos de reunificar organizaciones principalmente para realizar eventos conjuntos. Según Pereyra, a pesar de que algunas organizaciones bolivianas fueron fundadas por líderes con experiencia de militancia, la mayoría se auto-define en torno a aspectos primariamente culturales, deportivos y económicos, y presentan un énfasis menor en la afiliación a partidos políticos concretos.

Por un lado, los grupos de danza o fraternidades juegan un papel central en la vida social de la comunidad, principalmente en los mega-eventos religiosos y culturales como las festividades patronales que son uno de los espacios más importantes de encuentro entre bolivianos en Argentina ${ }^{19}$. Por otro lado, las ligas deportivas, principalmente aquellas relacionadas al fútbol, son actualmente importantes espacios para la creación de un sentido de pertenencia ${ }^{20}$. Otros grupos han emergido relacionados con actividades económicas y de inversión en mercados, como la Asociación de Feriantes Latinoamericanos que organiza la Feria Urkupiña en La Salada, una zona crucial para la industria textil ${ }^{21}$. La Colectividad Boliviana de Escobar, fundada en 1990, reúne a casi 500 miembros en dos grandes mercados en los cuales se venden frutas y verduras, un negocio con grandes beneficios lo cual ha convertido a esta organización en una de las más poderosas de la comunidad (Pizarro, 2007). Y también la feria del Parque Indoamericano (Canelo, 2011).

Periódicos de ambas colectividades dan cuenta de la gran diversidad de actividades que desarrollan estas organizaciones que van desde movilizaciones

${ }^{19}$ De hecho, la Asociación de Conjuntos Folklóricos Bolivianos (AFABOL) fue creada después del año 2000 y, a pesar de no ser muy popular entre los residentes, reunió a casi todas las fraternidades de danza.

${ }^{20}$ Un ejemplo es la Fraternidad Deportiva Boliviana (FRADEBOL) que fue fundada en 1989; sin embargo, existen casi 20 asociaciones con más de 500 equipos y 6000 participantes. Otra institución importante es la Asociación Deportiva Altiplano (ADA) que reúne a 70 equipos.

${ }^{21}$ Otras organizaciones económicas son aquellas de comerciantes en Liniers y Escobar, barrios que pueden ser definidos como en clave étnica. El último ha sido ampliamente estudiado por Roberto Benencia debido a la asombrosa productividad de la unidad agrícola de los "quinteros" bolivianos. 


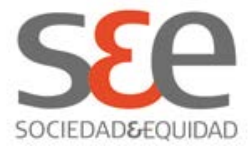

políticas, festividades religiosas, conmemoraciones cívicas y festivales artísticos de música y danza, hasta talleres de formación, concursos varios, encuentros con personalidades destacadas y reuniones privadas, incluidas las asambleas de las propias comisiones directivas de las instituciones. Esto muestra la importancia y el peso que las asociaciones bolivianas y paraguayas han ido adquiriendo con el tiempo en la vida de los residentes de esos orígenes y sus familias, quienes participan de las actividades ofrecidas por las organizaciones en grado variable ${ }^{22}$. En términos comparativos, si a los bolivianos se los suele definir casi exclusivamente como migrantes económicos, los paraguayos se ven mayormente atravesados por el exilio político. Esto tiene impacto en los modos de participación de ambos colectivos. De ahí resulta que mientras que las instituciones bolivianas se definen principalmente en torno a objetivos religiosos y culturales, las paraguayas lo hacen con más frecuencia en relación a metas políticas, e incluso vinculados a la actividad de partidos políticos concretos del lugar de origen (aunque esto siempre es motivo de disputas entre líderes y organizaciones). Por otro lado, también se observan diferencias en los tipos de liderazgo, en tanto que algunos dirigentes poseen experiencia previa de participación y militancia en tanto que otros aprenden recién en el contexto migratorio, y esto difiere de una comunidad a otra (Gavazzo, 2006) ${ }^{23}$. En este sentido, se observa un universo altamente heterogéneo de instituciones y prácticas asociativas que incluyen desde clubes barriales, asociaciones de ayuda mutua, conjuntos de danza y música, cooperativas de trabajo, programas de radio y grupos de reflexión, entre muchos otros. Cada una de estas organizaciones tiene sus propios objetivos, reclamos, interlocutores, alianzas y modo de auto-presentación y apelo a los compatriotas y sus familias.

Las organizaciones comunitarias constituyen el primer escalón en el cuadro de posibilidades de participación de los inmigrantes latinoamericanos, especialmente de los bolivianos y paraguayos. Son las que están más cerca de los sujetos migrantes, por lo tanto las que primero entran en contacto con los problemas que los aquejan y quienes deben en principio buscar soluciones. Sin embargo, existen numerosos organismos dedicados al tratamiento de la

\footnotetext{
${ }^{22}$ En los periódicos El Renacer de Bolivia en Argentina y Ñañe Retá vemos registradas numerosas notas referidas a las actividades de los centros y asociaciones de ambas comunidades a lo largo de varios años. A pesar de su de acopio constante, resulta imposible analizarlo como se debería en esta tesis, aunque parece importante dejar constancia de la riqueza de este material para futuros análisis de las organizaciones.

${ }^{23}$ Dicha experiencia en el caso boliviano en ocasiones se refiere a la participación en actividades sindicales o comunitarias en el sentido de los pueblos originarios (principalmente quechua y aymara) en tanto que el paraguayo se vincula mayormente a la experiencia campesina y partidaria (también sindical).
} 


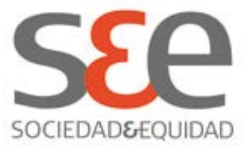

cuestión migratoria y a la defensa de los derechos de los inmigrantes. Con respecto a las organizaciones extra-comunitarias, y tal como consta en la bibliografía especifica (Pereyra, 2001; Novick, 2004; J elin, 2006; Badaró, 2006; Courtis 2006), existen distintos organismos dedicados a la "problemática migratoria" en el país, tanto del Estado como ONGs. Es con ellos con quienes los migrantes y sus instituciones entran en contacto y a partir de los cuales construyen determinadas representaciones e imágenes no sólo del Estado argentino sino además de sí mismos como ciudadanos y/o extranjeros. Asimismo, son sus funcionarios quienes se encargan de implementar tanto las leyes como las políticas vigentes en la vida cotidiana de los migrantes y es por eso que pueden definirse como agentes estatales (Canelo, 2011).

Por esta razón, se deben estudiar dos tipos de instituciones: comunitarias y extra-comunitarias. En cuanto a las primeras, como vimos, se incluyen asociaciones y organizaciones de diversa índole -políticas, culturales, deportivas, barriales, federaciones, entre otras- que han surgido históricamente a partir de la conformación de redes entre los migrantes, en este caso, paraguayos y bolivianos. Respecto de las extra-comunitarias, existen dos subtipos: agencias del estado y organizaciones no gubernamentales. Es que estas organizaciones, con sus subtipos, conforman una estructura institucional heterogénea en la que los migrantes bolivianos y paraguayos -y a sus hijosdisputan un lugar como actores sociales y políticos legítimos.

\section{La participación de los hijos en las asociaciones de las comunidades migrantes}

La estructura asociativa hasta aquí descripta funciona como marco para la participación de los hijos. Debemos observar en qué tipo de organizaciones se sienten cómodos para actuar y cumpliendo qué roles, partiendo de sus propios testimonios y desde su propia perspectiva. Se parte de pensar que la participación en asociaciones como las aquí analizadas constituyen un punto de partida para comenzar a involucrarse en otras luchas políticas, que exceden las que se derivan de la construcción de la idea de que son "extranjeros" (o sea, de la "alterización" planteada en la Parte II). Puesto que las organizaciones de la sociedad civil juegan un papel importante en la inclusión o exclusión de los inmigrantes limítrofes en Argentina, puede que también afecte las vidas y experiencias de sus descendientes. Pero ¿qué actividades desarrollan los hijos en función de promover el reconocimiento de su identidad migratoria? ¿Continúan con las aprendidas de sus padres o crean nuevas? ¿Cómo son las trayectorias de participación de los hijos de bolivianos y paraguayos en el AMBA?

J osé Luis, hijo de padres bolivianos, de 36 años, tiene una larga historia de participación en organizaciones de la comunidad boliviana. Como en muchos 


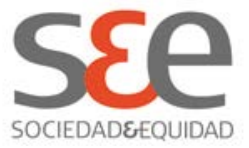

otros casos, sus comienzos se dieron a partir de las danzas: "Claro; bailé. Bueno como todo; pata dura que empecé con un poquito de baile; jugaba a la pelota; ese fue otro motivo que me acerqué ahí, no digo desesperado, pero cuando Ilegué, tenían un equipo, fui; también trabajé el idioma. Y, en esto, claro, me apasionó tanto esto porque evidentemente, es un proceso de desarraigo. Por eso te digo, cuando yo tenía 15, 16 años, ponían música, era un desastre, yo me peleaba". La música y el deporte constituyen atractivos fundamentales para que los hijos se interesen por participar de la vida asociativa de ambas comunidades. Con el paso de los años, J osé Luis Ilegó a ser presidente de un importante centro de la comunidad boliviana entre los años 2001 al 2007: "Primera vez que tenían un presidente hijo. La primera vez y, aparte de eso, con toda una problemática ¿no? porque evidentemente nosotros veníamos trabajando en el tema cultural; buscar la cultura, justamente, me Ilevó a que yo fuera presidente. (...) entré buscando cultura y, a los 3 meses, entré como presidente. Eso me catapultó, pero hicimos bien las cosas en ese aspecto".

Justamente, la apertura despertó en él un interés mayor. Tal como relata, una vez en la presidencia y con todas las ganas de contribuir a la institución, J osé Luis comenzó a encontrar problemas con los socios y dirigentes mayores: "A mí me tocó 12 años pelear con los viejos; "Ios viejos" es una manera de decir. Yo me presenté en 3 elecciones y salí en 3 elecciones (...) Mientras yo bailaba y traía cosas de la colectividad, estaba todo bien. Ahora, cuando yo quise la parte política y ahí fue el problema ¿entendés? Por el poder, por decir "No, pero si yo estoy desde hace mucho tiempo, vos no vas a venir a cambiar". Según el no hay una verdadera apertura de los dirigentes más antiguos hacia los más nuevos: "Yo los conozco a todos (dirigentes). De 45 / 50 años para arriba. Lo que puede haber recién ahora son movimientos que sí, hay jóvenes, qué sé yo, pero no instituciones conformadas societarias, no hay; todas son como te digo. $Y$ en sus temas, tienen todos profesionales; en general, el profesional tiene poder, capital económico (...) Y lo sienten como un desarraigo, como que alguien les va a robar eso."

Es interesante que José Luis identifique a esos dirigentes mayores con una clase socio-económica ya establecida que marca una diferencia, pero sobre todo una asimetría, una desigualdad entre ellos ("Ios nuevos") y nosotros ("Ios que venimos peleándola desde siempre") en donde la comunicación y el consenso necesarios para la acción colectiva se ven dificultadas. Como se mencionó, la inserción de "nuevas camadas" de dirigentes jóvenes es ocasionalmente acompañada de una disputa de poderes con los ya establecidos y en ejercicio desde hace años. En ese sentido, los conflictos entre dirigentes jóvenes y mayores deben ser entendidos de acuerdo al modelo ya utilizado para analizar las relaciones de poder (Elías y Scotson 1994, Elías 1998). Así, resulta 


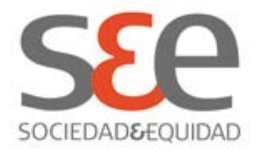

lógico que J osé Luis perciba que sus problemas con el Centro comenzaron justo cuando quiso involucrarse en otros asuntos, y no sólo la danza, es decir debido a las diferencias que él tenía con "Ios viejos":

"Cuando uno empieza a trabajar, se da cuenta también de que hay otra problemática: dirigencial 0 sea, la sociedad busca un referente para, justamente, salvar su culpa; para eso son las instituciones. Y las instituciones están regidas por gente que también tienen problemas contra sus pares y también tienen problemas entre sí. Por eso es que ninguna institución puede salir adelante porque tienen esos problemas. Nosotros venimos de una sociedad que hay diferencias de clases y están muy bien marcadas. $Y$ eso hace que nosotros por ejemplo, como sociedad, siempre tendamos al paternalismo de alguien y ia quiénes buscamos? A los profesionales, a aquellas eminencias que son mejores que nosotros. Y claro; cuando Ilegan, esas eminencias lo que hacen es marcar esa diferencia de clases; lo primero que hacen. Entonces ¿qué pasa? La sociedad, cuando piensa en ese proyecto, los empieza a presentar, porque es aparte eso; vos tenés que integrar; no tenés que descentralizar o poner castas; yo creo que se da en todas, en todas las instituciones se da igual. Vos fijate que la dirigencia es toda de médicos, ingenieros, pero siempre se da así.

Nuevamente las "diferencias generacionales" pueden implicar también "diferencias de clase", entre otras desigualdades. Esto se aplica sobre todo cuando las generaciones se definen a partir de los diferentes momentos de arribo al país por parte de los padres, puesto que los hijos van viviendo coyunturas sociales y políticas particulares que -a lo largo de las diferentes edades, como vimos en la tesis (Gavazzo, 2012)- generan diferenciaciones también dentro del grupo de descendientes. Para José Luis, por ejemplo, existen diferencias entre: "Ios que venían en los '60, '50, con los que vinieron en los '80, '90; existe una gran diferencia. Sobre todo educacional; hay una barrera; es un problema eso. Esa generación se encuentra con los hijos y ahí se crea un problema. Ellos cuestionan que nosotros no somos bolivianos. Nos critican porque somos de la misma generación; nosotros "no somos bolivianos"; no podemos tomar las insignias, los símbolos".

Entonces los conflictos se dan no sólo con los dirigentes mayores sino con los coetáneos nacidos en Bolivia o Paraguay. Por estos motivos, luego de 


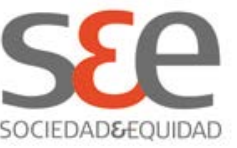

intentarlo por varios años, José Luis actualmente dice no creer en las organizaciones como medio para mejorar la realidad de la comunidad:

Uno, siempre, en esa perspectiva, en esa mirada de transformar las cosas, con una intención en la cual ir modificando; o sea, tratando de tener una institución representativa; tratando de tener una institución que sea participativa, uno puede ayudar al cambio. $Y$ en ese momento, pensaba que era así; hoy en día pienso que me equivoqué totalmente porque no era por ese lado por donde se podía cambiar. No es por una institución o no es por algo de esa naturaleza que uno vaya a cambiar la situación de los bolivianos; al contrario, lo que uno crea, posiciona un proceso nada más pero no sería la utilidad o darle, buscarle desde una institución que eso vaya a ser como un derrame, que todo vaya a ser en armonía y que podamos llegar a la problemática, a solucionarla al contrario. Si nos metemos en una institución, lo único que creamos, son más problemas.

Es interesante que José Luis dijera esto cuando en el momento de la entrevista estaba fundando una nueva institución, una que -según cuenta- sería "diferente" de este otro tipo de organizaciones de las que quiso distanciarse. En todo caso, existen conflictos entre líderes de diferentes generaciones, sean éstas genealógicas (padres e hijos) como etarias. Diferencias en el modo de encarar las alianzas o en cuanto a los objetivos de las instituciones se van observando a lo largo de la vida participativa de los hijos que primero se insertan en espacios particulares como los grupos de danzas o de recreación de las mismas pero que van cambiando a lo largo de su crecimiento llegando incluso, ya después de los 25 o 30 años, a disputar espacios de decisión como las comisiones directivas. Aparecen entonces acuerdos y conflictos a la hora de actuar colectivamente que se traducen en una competencia inter-generacional por el poder de controlar dichas prácticas asociativas (Gavazzo, 2006). Las disputas con la generación de los dirigentes mayores es una constante entre los entrevistados que más se han dedicado a participar del mundo de las asociaciones de ambas comunidades. Con algunas diferencias notables entre quienes vienen de familias con trayectoria de participación política y social tanto en el país de origen y de destino, y aquellos que no contaban con ese capital social al momento de ingresar en alguna asociación de la comunidad.

Fernando ya vivió gran parte de estas experiencias. Actualmente tiene 50 años y es hijo de ambos padres paraguayos, pero confiesa no haber tenido grandes problemas para abrirse camino en la organización de la que forma 


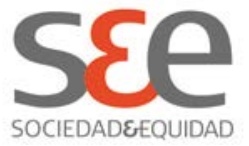

parte del desde el año 1985, el Club Deportivo Paraguayo. Incluso fue presidente del mismo en el año 2006, por un lapso de dos años.

vine acá y encontré mi lugar en el mundo, me abrieron las puertas, participé, era hijo de un paraguayo conocido de la dirigencia, a mí se me facilitó, la única traba que tuvimos era ser jóvenes, la dirigencia en ese momento nos acusaba de ser jóvenes, se nos acusaba de tilingos, imberbes, y nosotros les decíamos, aguantamos el embate, pero después les dijimos, "bueno pero basta, no nos acusen de ser jóvenes porque los vamos a acusar de ser viejos,"...y les ganamos la elección el 17 de agosto de 1986, fue la primera elección multitudinaria en la colectividad paraguaya, habrán participado 400 socios más o menos, donde el paraguayo votaba por primera vez, muchos paraguayos votaban por primera vez en el exterior y por primera vez en su vida.

El interés de Fernando en participar, según cuenta, no es igual en otros descendientes: "no se da mucho, es una lástima realmente, pero la juventud está descreída de la dirigencia política, o sea el Paraguay tiene un $87 \%$ de su población que no supera los 25 años, súper jóvenes y muchos ejemplos de buena conducta en la dirigencia paraguaya política no ha dado, así que en ese sentido son muy descreídos y no hay participación no hay conciencia, pero eso se da." Lo que sí observa es que sus compatriotas participan más a nivel barrial. Según Fernando la baja participación de los hijos en las instituciones se da porque no hay un interés de las generaciones mayores de dirigentes de incorporarlos, de involucrarlos en la vida asociativa:

el paraguayo se siente paraguayo y lucha por mantener y es un sacrificio enorme, mantenerse paraguayo afuera y tenés un montón de conflictos, el paraguayo lucha por mantener su origen pero sin embargo deja que sus hijos ya no pertenezcan a la colectividad paraguaya, no los retienen, muy poco son los que hacen eso. Entonces yo como dirigente insto a todos los padres paraguayos, que si los hijos no se sienten paraguayos no es problema de los hijos, eso es un problema de educación de los padres, que no les dimos las herramientas necesarias para que su hijo se sienta orgullosos de ser argentino pero de no renunciar a sus orígenes paraguayos" (...) "yo tengo un primo mío que reniega de ser paraguayo, pero sus mamá nunca le habló y él se aisló, o sea no se acercó a la 


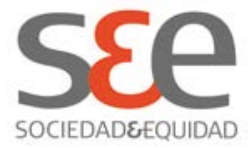

comunidad paraguaya, y entonces se perdió" (...)“cuando uno está frágil culturalmente, es lógico que vos te sientas inseguro, cuando viene un campesino de Paraguay, del campo, no conoce Asunción, viene a Buenos Aires, es un cambio enorme, es como ir de la Tierra a J úpiter.

Ciertamente la voluntad de los padres por involucrar a sus hijos en la vida comunitaria es fundamental, tal como se ha analizado en la mencionada tesis (Gavazzo, 2012). Por este motivo, resulta evidente que sólo una parte de los descendientes cuentan con el capital social de una familia con conocimientos acerca de las formas de organización legítimas y eficientes, y contactos y relaciones sociales influyentes. Los otros deben hacerse de herramientas propias para disputarle autoridad a las generaciones mayores en el mundo de las asociaciones, o bien "hacerse a un lado". En ese sentido, Fernando sabe que tuvo el camino allanado gracias a la constante participación de su padre en el ámbito de la política paraguaya y de los paraguayos en Buenos Aires. Esto también generó en él una voluntad de compromiso con la institución, y le valió un enorme respeto entre los colegas de su padre que se lo transfirieron -aquí también cuasi-biológicamente- al hijo. La formación política en la familia y el espíritu de Fernando fueron elementos clave en el ascenso dentro de la institución: "Y cuando vos sentís que podes dar mucho y cuando vos ves que la gente espera de vos mucho, entonces el compromiso es doble y si le querés sumar a esto la formación, un homenaje a mis padres, a mis abuelos, que entregaron sus vidas por cambiar un Paraguay, por soñar un Paraguay distinto, que no lo lograron y para mí era una continuidad de esa lucha." Para los hijos, comenzar a participar de una institución puede significar sentirse "más boliviano" o "más paraguayo". Y con el tiempo, eso puede resultar en relaciones duraderas porque "entrar en una institución paraguaya es entrar a un pedacito de tierra paraguaya, por qué? Porque mantenés el idioma, están tus compatriotas, comes tu comida típica, escuchas tu música, sos vos, tomas tereré, hablas de tus problemas, buscas la solución de tus problemas".

Hay otros casos más difusos, sobre todo el de los hijos que nacen en el contexto de una familia mixta (es decir de varias nacionalidades), numerosa y sin grandes lazos con la "comunidad". Tal es el caso, de Víctor de 35 años, hijo de padre paraguayo y madre boliviana quien, entre los años 1998 y 1999, tuvo un centro cultural en Banfield en el sur del GBA con unos amigos. También tuvo un programa de radio, en radio Nacional. Desde hace unos 4 o 5 años, participa de una Asociación Civil que se llama ABE, Asociación Barrial Educativa, que trabaja en la Villa 31. "Entré porque se necesitaba una persona que dé Taller de serigrafía. Y entré por ahí. Y después me dijeron si quería ser parte de la Asociación Civil, y dije que sí. Ahora soy vocal". En el taller que daba comenzó a ver que había "muchas personas que eran de Bolivia, señoras. Había de 


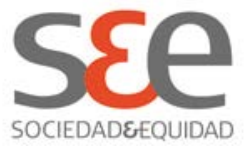

Paraguay (mayoritariamente señoras). Y después estaban las Madres de Plaza de Mayo Línea Fundadora". También trabaja en el Centro Popular de Mataderos, en un pasillo de Villa 15, barrio más conocido como Ciudad Oculta. Aunque actualmente dicta el taller de serigrafía, cuenta que antes trabaja de alfabetizador y que esa experiencia lo acercó a otros descendientes como él porque "en la villa hay gente de Perú, gente de Bolivia, gente de Paraguay, uruguaya...y es como que ahí se ve eso. En el costadito de la ciudad está todo eso". Cuenta que cuando sus alumnos se enteran de que su mamá es boliviana y que su papa es paraguayo eso "hace que ellos se sientan más cómodos. Pasa eso. Que pueden hablar de otras cosas, con más soltura, viste? Con otras cosas que dan por entendido que yo sé, o sea que no tienen que explicar cosas que a otro sí tendrían que explicarle".

En este sentido, el ser descendiente puede constituir una "ventaja" en tanto le permite "llegar mejor" a otros descendientes como él, con el fin de generar conciencias en ellos al respecto de sus propios derechos y también una revalorización de la pertenencia de sus padres, y la suya propia al universo de ellos, algo que es el objetivo de varios grupos de hijos. Al respecto, Víctor opina que es importante que los hijos participen de las organizaciones porque así algunos "se hacen cargo" y de ese modo le aportan a las sus padres "Io que por mucho tiempo ellos tuvieron que sostener. Eso de quizás, al principio no tener papeles y tener complicaciones para ir a, no sé, al médico...etc. Es como una reivindicación, se puede decir". Y esto tiene un valor positivo, tal como ilustra con el caso de un amigo de él "que es también hijo de boliviana y de un jujeño. Igual, es como mucha gente de Jujuy, niega a la vez que son descendientes de bolivianos, pero ahora como que está todo bien, dicen "Sí, mi abuelo era boliviano". Antes lo negaba".

Desde este pensamiento, los hijos tal vez logren lo que los padres no consiguieron del todo, es decir una "mayor integración" a la sociedad porteña y argentina, no sólo en términos de los sentimientos de pertenencia y los lazos afectivos sino también en cuanto a sus derechos básicos (como el de participar y organizarse). Sin embargo, la negación del origen de la que hablan varios entrevistados podría dificultar que el hijo sienta la necesidad y asuma el compromiso de participar en una institución comunitaria. Por eso, la educación de los padres resulta central, aunque para Víctor en general los padres no se preocupan por fomentar esa participación y ese reconocimiento en los hijos "quizás porque ellos, o en mi caso particular, vieron lo que pasaba en la dictadura, que las personas que se manifestaban, no llegaban. $Y$ me parece que también eso es muy fuerte. Lo que pasa que hubo muchas generaciones después de ahí que llegaron, hijos". 


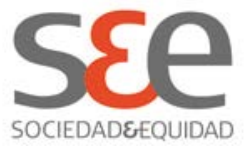

En relación a esto, es importante indagar en las percepciones de los hijos respecto de los problemas que enfrentan sus padres migrantes y otros ciudadanos de otros países que residen en Argentina, para saber si los consideran propios o no, y si procuran dar solución o no. En cuanto a eso, Gustavo M tiene 37 años, vecino de Ingeniero Bunge, en el Partido de Lomas de Zamora, al sur de GBA, es hijo de ambos padres bolivianos y participó de numerosas organizaciones. Cuando se le pregunta por los problemas que tienen los migrantes bolivianos, comenta que el más grave es "la integración de los jóvenes; hay que ayudar al tema de educación a través de los chicos migrantes ¿no? Y la cuestión laboral, dentro de la cuestión de los derechos humanos en general". O sea que una de las peores problemáticas que enfrenta la comunidad, boliviana al menos, es no estar ocupándose de los hijos más jóvenes. Gustavo M insiste en que no hay un gran compromiso colectivo por parte de las organizaciones existentes con la intención de cambiarlo porque "del $\mathbf{1 0 0 \%}$ de la población boliviana en la ciudad de Buenos Aires, el 0,5 participa en las organizaciones; nadie participa (...) Sí; si decimos que hay 200.000 bolivianos ¿cuántos chicos participan? 300, 400, 1000."Ciertamente existe un consenso respecto de la "relativamente baja participación" tanto en la generación de padres bolivianos y paraguayos como de sus hijos. Según Gustavo, en la colectividad boliviana "tenemos una cuestión negativa que el desentendimiento de los hijos de bolivianos. Ahí le resta, porque... bueno, migraste hace 10 años, 4 años, ahora... No, porque tiene una vida ¿te das cuenta? El tema es qué pasa con los hijos; es un proceso; ojalá que algún día se llegue a decir "Tengo que aportar mis 10 pesitos, mis 5 pesitos, mi asociación y demás". No existe esa cuestión".

Existen algunas diferencias entre comunidades que deben ser entendidas no sólo en el marco de las historias nacionales sino también en el del contraste en el discurso oficial entre "aquella inmigración europea" y "la de ahora", base del relato xenófobo que en ocasiones se proyecta también sobre los descendientes de los latinoamericanos. Para Fernando por ejemplo existen notables diferencias entre "el paraguayo" y "el boliviano (que) mantiene más, que tiene otro tipo de organización. Nosotros nos fuimos organizando a los golpes, por necesidad, para no perder las raíces, pero los bolivianos tiene organizaciones consolidadas, fuertes, tiene otra formación, otra participación, tienen más educación cívica, son más conscientes". Y para ilustrar eso recuerda que cuando a Evo Morales intentaron "tambalearlo" en el poder "hubo 20.000 bolivianos en la Plaza de Mayo" mientras que cuando a Lugo el Parlamento y la J usticia en el Paraguay, "Ios otros dos poderes que siguen igual", comenzaron a complicarle la gestión

“nosotros no sé si juntamos 1000, pero sin embargo nosotros acá juntábamos $8000,10.000$ personas en un campeonato de fútbol, en fiestas, en 


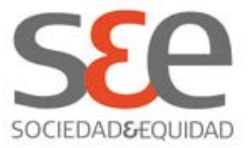

otras actividades, nosotros podemos movilizar muchísima gente, pero los bolivianos, cuando se trata de defender sus intereses, ellos tienen mucha más convocatoria, son más conscientes, más comprometidos". Y esto se ve "inclusive desde sus gobiernos" porque, tal como señala Fernando, hay más acciones "para que sus compatriotas estén acompañados en el exterior, caso totalmente distinto al paraguayo, nosotros fuimos expulsados y olvidados". En consonancia con esta idea, algunos feriantes paraguayos de La Salada, vecinos del barrio Lamadrid (aledaño a Ingeniero Bunge en Lomas de Zamora), se quejaban de la "baja participación" de los paraguayos en comparación con los bolivianos. Decían que eso se ve en la expansión comercial que éstos consiguieron en relación a sus propios compatriotas, y adjudicaban el éxito de los bolivianos a que tienen una "cultura organizativa" más desarrollada: "vos tenés 3 o 4 bolivianos y ya te arman una institución". Sin embargo, para Víctor la comunidad paraguaya se está comenzando a activar: "recién la veo teniendo un poquito más de...es como que tiene una negación hacia lo político, en general, eh? Desde unos años a acá veo que hay una mayor escucha hacia lo político".

En conclusión, las disputas inter-generacionales se dan en torno a ciertos capitales cuya puja define la reinvención del espacio político y social, razón por la cual el término generación constituye una categoría con capital simbólico propio (Kropff, 2008). Los usos de este término nos permiten explorar las disputas de sentido en torno a los procesos de comunalización, especialmente en la dimensión temporal, la construcción de tradiciones y sentidos de devenir, las apelaciones al pasado y las narrativas orientadas al futuro (Brown 1990 en Kropff 2008). Todo ello impacta en los modos en que los niños y los padres se identifican a sí mismos como parte de una misma comunidad de sentido y pertenencia, y también en las formas en que son vistos "desde afuera".

\section{Ciudadanía y participación: inmigrantes y descendientes en acción}

Los debates en torno a ciudadanía se han intensificado en la última década, redefiniendo derechos y deberes de los individuos y grupos que componen una nación. En ese proceso, la obtención del status de ciudadano -como vimos en el caso de los hijos de bolivianos y paraguayos nacidos en Buenos Aires- no es garantía de cumplimiento de derechos, especialmente en el caso de los inmigrantes. De este modo, como apunta Pereyra (1999), la ciudadanía no garantiza la igualdad y menos aún cuando las migraciones complejizan la adquisición de ese status que es justamente lo que legitima y habilita la conciencia de ser "sujeto de derechos" ${ }^{24}$. En este contexto, los extranjeros

\footnotetext{
${ }^{24}$ Según la autora, esta relación entre la ciudadanía y la extranjeridad se inserta en un sistema de sociedad moderna funcionalmente diferenciada lo que implica una inclusión parcial de ciertos sectores como los generados por la inmigración.
} 


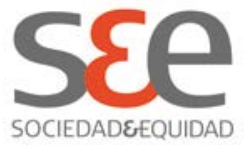

frecuentemente no son percibidos como "ciudadanos plenos" y, tal como vimos, esto se comporta como una condición que se "transmite" o "transfiere" a sus descendientes. La ciudadanía representa entonces la frontera entre la inclusión y la exclusión en importantes esferas de la vida pública, constituye la barrera que legaliza e institucionaliza la exclusión de los inmigrantes. Es por eso que la ciudadanía excluyente es un mecanismo de selectividad y control de los inmigrantes, que está en el fondo de los intentos de las sociedades "receptoras" por asimilar o integrar a los inmigrantes "pero en condiciones que no pongan en peligro el orden público establecido y respetado por sus ciudadanos" (Fornet-Betancourt 2003:151). Esto es la "asimilación" e "integración" a un orden que les "cede" una participación controlada en el espacio público. En todo caso, los hijos tienen la ventaja de tener la nacionalidad argentina y, en función de ella, legitimar su participación frente a sí, sus familias y sus "otros".

Por eso, si la ciudadanía es un "status que garantiza a los individuos igualdad de derechos y deberes, libertades y restricciones, poderes y responsabilidades" (Held, 1997, Pereyra, 1999:12), se debería garantizar el otorgamiento creciente de derechos de ciudadanía para que todos los grupos y personas sean tratados como miembros plenos en una sociedad de iguales. Es cada Estado el que define los derechos y deberes para la población, extranjeros 0 nativos, diferenciales entre éstos y también al interior de los primeros. Por eso, en el caso argentino "se generan distintos criterios de diferenciación y jerarquización que catalogan a algunos grupos como especialmente problemáticos, mientras definen a otros como potenciales contribuyentes al desarrollo del país" (J elín, 2006:48). A partir de eso, cada grupo desarrolla su propia estrategia de inserción y de definición de su lugar en la sociedad argentina, como hemos visto hasta aquí. En el marco de cierta configuración institucional, de ciertos marcos legales, políticas públicas y de discursos (analizados en la tesis mencionada), el estudio de las estrategias de las organizaciones bolivianas y paraguayas a través del testimonio de sus líderes, especialmente el de los dirigentes que son jóvenes descendientes, nos permite determinar el modo en que esas estructuras funcionan como oportunidades $u$ obstáculos para la acción y ejercicio de la ciudadanía.

A partir de las observaciones y entrevistas, se puede afirmar que los hijos de bolivianos y paraguayos a los que nos referimos utilizan las redes sociales e instituciones creadas por sus padres migrantes dentro de los límites que éstos mismos les imponen. También de acuerdo a la tolerancia y vocación de activismo que tenga cada sujeto en particular. Al mismo tiempo, los hijos crean nuevos proyectos colectivos en donde pueden fijar las propias reglas y establecer sus propios móviles y parámetros de acción. Sobre todo los más jóvenes en ocasiones se involucran en la innovación de prácticas artísticas y 


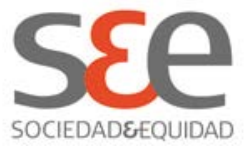

estéticas vinculadas al país de origen en relación a metas y compromisos nuevos. La apertura de nuevos espacios de participación, lejos del alcance de los padres (aunque a veces no del todo ajenas), se ve impulsada además por los conflictos que se generan en las instituciones más importantes de ambas comunidades en relación a los límites que -desde la visión adulta- deben respetar los dirigentes más jóvenes. Asimismo el estigma mencionado al inicio que parece estar influyendo también en la "ausencia de participación" en la vida asociativa de las "comunidades". Se debe tener en cuenta que otros entrevistados en la mencionada tesis, nunca participaron de ninguna asociación, ni institución, a pesar de ocasionalmente acceder a los mercados culturales étnicos, como las fiestas, los restaurantes y algunos espectáculos y eventos deportivos. Estos elementos también determinan que muchos de los hijos encaren una reivindicación de su "cultura de origen", a pesar de que puedan no hacerlo desde el marco institucional dado. En todos los casos resulta imposible afirmar una linealidad en la relación de los hijos con el origen familiar, razón por la cual en vez de "transmisión de padres a hijos" resulta más adecuado referirse a la creación permanente de una memoria compartida que - al ser altamente heterogénea- determina identificaciones diferenciales y desiguales entre las distintas generaciones. $Y$ esas identificaciones constituyen materia prima para la formación de nuevos líderes en ambas comunidades de migrantes.

En todo caso, "la emergencia de sociedades étnicas de ayuda mutua, de instituciones culturales y la organización política incipiente permiten fortalecer la posición de la comunidad vis-à-vis la sociedad hegemónica, y pueden constituirse en canales legítimos para reclamar reconocimiento" (OIM-CEMLA, 2004:13). No obstante, la incorporación política sólo es posible en sociedades que aceptan a los inmigrantes como ciudadanos y no meramente como poblaciones inmigrantes residentes, socialmente integradas pero políticamente excluidas. Si los bolivianos y paraguayos se reconocen como sujetos de derechos, si las disputas internas logran dirimirse entre ellos, si existen líderes que puedan representar sus intereses colectivos, si las organizaciones comunitarias son reconocidas y convocadas, si las políticas públicas apuntan no sólo a concientizar a los migrantes sino a generar una reflexión al nivel de la sociedad toda, y si los líderes jóvenes encuentran espacios reconocidos de expresión y para la acción colectiva, estaremos más cerca de una participación ciudadana plena no sólo para los migrantes y sus hijos sino para todos los que aquí convivimos, y también de crear sociedades -un poco al menos- más justas e igualitarias. 


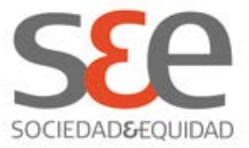

\section{Referencias Bibliográficas}

Badaró, M. (2006). "La conciencia y la ley: la cuestión migratoria en las prácticas de agencias estatales y organismos no gubernamentales en la ciudad de Buenos Aires". En: Grimson, A y Jelin, E. (Comp) (2006) Migraciones Regionales hacia la Argentina. Diferencia, Desigualdad y Derechos, pp-207-235. Prometeo libros. Buenos Aires.

Balán, J. (1982), "La economía doméstica y las diferencias entre los sexos en las migraciones internacionales: un estudio sobre el caso de los bolivianos en Argentina." En: Estudios Migratorios Latinoamericanos. Año 5; No 15-16. pp 269-294.

Bargman, D. y otros. (1992). "Los grupos étnicos de origen extranjero como objeto de estudio de la Antropología en la Argentina". En: Hidalgo C., Tamagno, L. (eds.) Etnicidad e identidad., pp.: 189-198. CEAL. Buenos Aires.

Beheran, M. (2007). El tratamiento de la diversidad cultural en las escuelas públicas primarias de la ciudad de Buenos Aires. Tesis correspondiente a la Maestría en Políticas de Migraciones Internacionales, Universidad de Buenos Aires. Buenos Aires, Argentina.

Benencia, R. (2003). "La inmigración limítrofe" En: Devoto, F. Historia de la inmigración en la Argentina. Editorial Sudamericana. Buenos Aires.

Bruno, S. F. (2008). "Proceso migratorio paraguayo hacia áreas urbanas en Argentina: Gran Buenos Aires, Gran Posadas y Formosa. Trayectorias territoriales y laborales". En taller: Paraguay como objeto de estudio de las ciencias sociales, Grupo de Estudios Población, Migración y Desarrollo. Instituto de Investigaciones Gino Germani. Facultad de Ciencias Sociales, Posadas, Misiones.

Caggiano, S. (2004). "El Centro de Estudiantes Bolivianos de La Plata". Ponencia presentada en: Congreso Argentino de Antropología Social. Villa Giardino, Córdoba.

Caggiano, S. (2005). Lo que no entra en el crisol. Inmigración boliviana, comunicación intercultural y procesos identitarios. Prometeo Libros. Buenos Aires.

Canelo, B. (2011). Migración, Estado y Espacio Urbano. Dirigentes Migrantes Bolivianos y Agentes del Gobierno de la Ciudad de Buenos Aires ante Disputas por Usos de Espacios Públicos. Tesis doctoral. Mimeo. Buenos Aires.

Courtis, C. (2006). “Hacia la derogación de la Ley Videla: la migración como tema de labor parlamentaria en la Argentina de la década de los '90". En: 


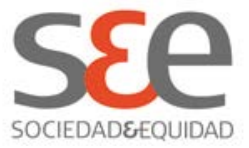

Grimson, A.; Jelin, E. (compiladores): Migraciones regionales hacia la Argentina. Diferencia, desigualdad y derechos. Prometeo Libros, Buenos Aires, Argentina.

Courtis, C; Pacceca, M. (2007). "Migración y derechos humanos: una aproximación critica al "nuevo paradigma" para el tratamiento de la cuestión migratoria en la Argentina". En: Revista J urídica. Buenos Aires.

Devoto, F. (1992). Movimientos migratorios: historiografía y problemas. CEAL. Buenos Aires.

Devoto, F. (2003). Historia de la inmigración a la Argentina. Paidos. Buenos Aires.

Domenech, E. (2008). “La ciudadanización de la política migratoria en la región sudamericana: vicisitudes de la agenda global." En: Novick, S (comp.). Las migraciones en America Latina: Políticas, culturas y estrategias, CLACSO Ed, Buenos aires.

Elías, N; Scotson, J. (1994). Os Estabelecidos e os Outsiders. Jorge Zahar Edit. Brasil.

Elías, N. (1998). La Civilización de los Padres y Otros Ensayos. Norma. Bogotá.

Fornet-Betancourt, R. (2003). "Interculturalidad y Filosofía en América Latina". En: Internationale Zeitschrift fur Philosophie, Reihe Monographien. Aachen

Foucault, M. 1991 (1978). "La Gubernamentalidad". En: Varios Autores: Espacios de poder, pp. 9-26. La Piqueta. Madrid.

García Borrego, I. (2003) "Los hijos de inmigrantes extranjeros como objeto de estudio de la sociología." En Anduli: Revista Andaluza de Ciencias Sociales № 3, pp. 27-46. España.

Gavazzo, N. (2002). La Diablada de Oruro en Buenos Aires. Cultura, identidad e integración en la inmigración boliviana. Tesis de Licenciatura en Ciencias Antropológicas, Mimeo.UBA. Buenos Aires.

Gavazzo, N. (2006). "Immigrants in the Imagination of the Nation. Latin Americans in Argentina in the early 21st Century". Dissertation submitted for the MA Degree in Area Studies (Latin America), University of London, School of Advanced Studies, Institute for the Study of the Americas. Londres.

Gavazzo, N.( 2009). "Para todos los hombres del mundo: diversidad cultural y nación en algunos discursos públicos sobre la inmigración en Argentina". En: 


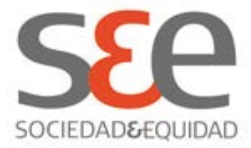

Viana Garces, A. (coord.) Repensar la Pluralidad, Fundación Universidad Carlos II y Editorial Tirant Loblanch, Madrid.

Gavazzo, N. (2012). Hijos de bolivianos y paraguayos en el Área Metropolitana de Buenos Aires. Identificaciones y participación entre la discriminación y el reconocimiento - Tesis Doctoral, Facultad de Filosofía y Letras, UBA.

Germani, G. (1987). [1955]. Estructura social de la Argentina. Editorial Solar. Buenos Aires.

Goffman, E. (1980) [1963] Estigma. Ed. Amorrortu. Buenos Aires.

Grimson, A. (1999) Relatos de la diferencia y la igualdad. Los bolivianos en Buenos Aires. EUDEBA. Buenos Aires.

Halpern, G. (1999). "El Club Atletico Deportivo Paraguayo". En: Trabajo presentado en el $I I 0$ Encuentro de Deporte y Ciencias Sociales. Área Interdisciplinaria de Estudios del Deporte. Facultad de Filosofía y Letras, UBA. Buenos Aires.

Halpern, G. (2005). "Y la ley hizo lo suyo...". En: Terceras Jornadas de Investigación en Antropología Social. Facultad de Filosofía y Letras, UBA. Buenos Aires.

Held, D. (1997). “Ciudadanía y Autonomía”. En: Agora N o 7,pp. 42-71.

Jelin, E. (2006). "Migraciones y derechos: instituciones y prácticas sociales en la construcción de la igualdad y de la diferencia." En: Grimson, A y Jelin, E. (Comp), Migraciones Regionales hacia Argentina. Diferencia, Desigualdad y derechos. Prometeo Libros, Buenos Aires.

Kropff, L. (2008). "Apuntes conceptuales para una antropología de la edad" En Avá, Revista de Antropología, Programa de Postgrado en Antropología Social de la Universidad Nacional de Misiones. Misiones, Argentina.

Lamounier, I. (2002) "Japanese Argentina Historial Overview" En: Encyclopedia of J apanese in the Americas. An Ilustrated History of the Nikkei,pp. 72-82. Ed. Akemi Kikumura. Yano, Japanese American National Museum.

Levitt, P; Waters, M. (2002). The Changing Face of Home. The Transnational . Russell Sage Foundation.

Maluendres, S. (1994). "De nuevo sobre las pautas matrimoniales de los migrantes y sus hijos piamonteses y leoneses en Trenel, Territorio Nacional de La Pampa, (1911-1940)". En: Estudios Migratorios Latinoamericanos, Revista Cuatrimestral, Número 28, 
Margulis, M., Urresti, M. (1999). La Segregación Negada. Cultura y Discriminación Social. Editorial Biblos. Buenos Aires.

Martinez Pizarro, M, Villa, M. (2001). "Tendencias y patrones de la migración internacional en America Latina y Caribe." En: Notas de Población № 73, CEPAL, Santiago, Chile.

Novaro, G. Borton, L. Diez, M. Hecht, A. (2008) "Sonidos del silencio, voces silenciadas. Niños indígenas y migrantes en escuelas de Buenos Aires" En: Revista Mexicana de Investigación Educativa. Vol. 13, Núm. 36. Mexico.

Novick, S. (2004). "Una nueva ley para un nuevo modelo de desarrollo en un contexto de crisis y consenso." En: Giustiniani, R. Migración: un derecho humano. Ley de Migraciones Nro. 25.871, pp.67-85. Prometeo libros. Buenos Aires.

OIM-CEMLA (2004). Relevamiento y diagnostico de las asociaciones de la colectividad boliviana en Argentina. Informe final. OIM-CEMLA. Buenos Aires.

Onaha, C. (2000). "J aponeses en Argentina y nikkei argentinos en J apón: el rol de la identidad nacional y étnica en un proceso de integración de los nikkei argentinos en Okinawa". En: X Congreso Internacional ALADAA, Río de J aneiro.

Oteiza, Novick, Aruj, (1997). Inmigración y Discriminación. Políticas y discursos. Grupo Editor Universitario. Buenos Aires.

Pereyra, B. (1999). "Los que quieren votar y no votan. El debate y la lucha por el voto chileno en el exterior". En: Cuadernos para el Debate № 9. IDES, Buenos Aires.

Pereyra, B. (2001). Organizaciones de Inmigrantes de Países Vecinos en la Construcción de Ciudadanía. Tesis de Maestría en Políticas Sociales. Facultad de Ciencias Sociales, UBA, Buenos Aires.

Pizarro, C. (2007). "La Colectividad Boliviana de Escobar". En: VII Reuniao de Antropologia do Mercosul. Porto Alegre, Brasil.

Portes, A ed. (1997). The Economic Sociology of Immigration. Essays on Networks, Ethnicity and Entrepreneurship. Russell Sage Foundation. New York.

Portes, A. y Rumbaut, R. (2001). Legacies: the Story of the Immigrant. Second Generation. Russell Sage Foundation. Nueva York.

Recalde, A. (2002). "Los inmigrantes de origen latinoamericano en la Ciudad de La Plata" En: Maffia, M. (org.) ¿Dónde están los inmigrantes? Mapeo 


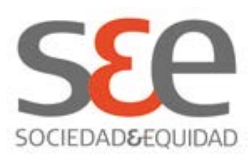

sociocultural de grupos de inmigrantes en la provincia de Buenos Aires. Ediciones Al Margen. Buenos Aires.

Sayad, A. (2011). La doble ausencia. De las ilusiones del emigrado a los padecimientos del inmigrado. Anthropos. Buenos Aires.

Segato, R. (2002). "Identidades políticas y alteridades históricas". En: Transnacionalimos, migraciones e identidades - Revista Nueva Sociedad № 178. Ed. Nueva Sociedad. Venezuela.

Sinisi, L (1999). "La relación "nosotros - otros" en espacios escolares multiculturales. Estigma, estereotipo y racialización". En: María Rosa Neufeld y Jeans Ariel Thisted (compiladores) De eso no se habla...." Los usos de la diversidad en la escuela. Eudeba Buenos Aires.

Vargas, J. (2006). La tierra no es sólo la Pachamama. Ponencia presentada en Seminario Migraciones y Ciudadanía Rosario. 